\title{
Red Blood Cell replacement or nanobiotherapeutics with enhanced red blood cell functions?
}

Professor TMS Chang, OC, MD, CM, PhD, FRCPC, FRSC,

Director, Artificial Cells and Organs Research Centre, Depts Physiology, Medicine \& Biomedical Engineering,

Faculty of Medicine, McGill University. www.medicine.mcgill.ca/artcell

Published later in Journal Artificial Cells, Nanomedicine and Biotechnology 43, 3, 145-147, 2015

\section{Abstract}

Why is this important?

Under normal circumstances, donor blood is the best replacement for blood. HOWEVER:

- Natural epidemics (e.g. HIV, Ebola etc) or man-made epidemics (terrorism, war, etc) can result in contaminated donor blood or disqualified disease contact donors. (unlike rbc, blood substitutes can be sterilized to remove infective agents)

- Heart attack and stroke are usually caused by obstruction of arterial blood vessels. Unlike rbc particles, blood substitute is a solution and in animal studies it can more easily perfuse through obstructed vessels to reach the heart and brain.

- Severe blood loss from accidents, disasters or war may require urgent blood transfusion that cannot wait for transportation to the hospital for blood group testing. (unlike red blood cells (rbc), blood substitutes do not have blood groups and can be given on the spot)

- Red blood cells have to be stored in refrigeration for up to 42 days thus difficult to transport and store in disaster and frontline. (Blood substitutes can be stored at room temperature for more than 1 year, compared to rbc of 1 day at room temperature)

- In very severe hemorrhagic shock there is usually a safety window of 60 min for blood replacement, beyond which there could be problems related to irreversible shock. Animal study shows that one type of blood substitutes with enhanced rbc enzymes may be able to prolong the time..

What is the present status around the world?

The first report of artificial cells includes artificial red blood cells (Chang, Science, 1964, Chang \& Poznansky, Nature, 1968, Chang, Nature 1971a) (with support from MRC Canada). Most people thought that blood substitute was a simple matter that could be quickly developed when needed. Thus blood substitute research was put aside and only the other areas of artificial cells were extensively developed around the world for wide spread uses (e.g. Chang Nature Rev Drug Disc 2005, Orive et al Nature Medicine 2003, Chang, 2007). When AIDS came in 1989 there was no blood substitutes and many patients were infected with H.I.V. contaminated donor blood. It was only then that intense R\&D on blood substitutes was belatedly carried out around the world. It was found out too late that blood substitute requires the same long-term research as in any other medical research for cancer and other diseases. Thus, the present status is only as follows (Przybelski et al 1996, Tsuchida 1998, Klein 2000, Kobayashi et al 2005, Winslow 2006, Zuck 2006, Liu \& Xiu 2008, Mozzarelli \& Bettati 2011, Zapol 2011,Yang, Liu, Zheng 2013, Chang 2013, Kim \& Greenburg 2014, Weiskopf 2014):

Red blood cells have 3 major functions: (1) transport oxygen from the lung to the tissue, (2) remove damaging oxygen radicals and (3) carry carbon dioxide $\mathrm{CO} 2$. from the tissue to the lung to be removed.

(1)Oxygen carriers (HBOCs): It is thus not surprising that after more than 20 years of R\&D around the world only oxygen carriers have been tested clinically. The most extensive clinical trials were based on polyhemoglobin (PolyHb) developed independently mainly by two groups (Northfield on human PolyHb and Biopure on bovine Poly $\mathrm{Hb}$ ) using the basic principle of glutaraldehyde crosslinked hemoglobin first reported by Chang (1971b). This has no blood groups and can be pasteurized to remove infective agents and can be stored at room temperature for more than 1 year. Large-scale clinical trials have been carried out (e.g. Gould et al, 2002, Jahr et al 2008) including using this in the ambulance without the need for typing or cross matching (Moore et al 2009). Oxygen carriers are commonly called "oxygen therapeutics". For some conditions, in addition to oxygen, there may also be a need for the other 2 red blood cell (rbc) functions: remove harmful oxygen radicals and transport $\mathrm{CO}_{2}$.

(2)Oxygen carriers + removal of oxygen radicals: This can be a soluble complex of Polyhemoglobin containing antioxidant enzymes to remove oxygen radicals (PolyHb-SOD-CAT) (D'Agnillo \& Chang Nature Biotech 1998). 
It can prevent ischemia-reperfusion injury in an hemorrhagic shock-cerebral ischemia (Powanda \& Chang 2002) (with support from CIHR and FRSQ). Conjugated hemoglobin containing synthetic antioxidants (PNPH) (Ma \& Hsia 2013) is another example. Others included those of Simoni et al (1997), Rousselot et al (2006), Jia \& Alayash (2013).

(3)All 3 rbc functions (Carries Oxygen + removes oxygen radicals + carries carbon dioxide). Other conditions as in sustained severe hemorrhagic shock may require all three rbc functions. With support from the $\mathrm{CIHR/Canadian} \mathrm{Blood} \mathrm{Service,} \mathrm{we} \mathrm{have} \mathrm{designed} \mathrm{a} \mathrm{novel} \mathrm{soluble} \mathrm{nanobiotechnological} \mathrm{complex} \mathrm{(PolyHb-}$ SOD-CAT-CA). It not only has all 3 rbc functions, but it can have enhancement of all 3 rbc functions by increasing the concentrations of rbc enzymes in the complex. These rbc enzymes can be extracted from rbc inexpensively (Guo, Gynn \& Chang 2015). This complex has no blood groups. The lyophilized preparation can be heat pasteurized at $68 \mathrm{~F}$ for $2 \mathrm{~h}$. This can be important if there is a need to inactivate H.I.V. virus, Ebola virus, and other infective organisms. Unlike about 1 day for rbc at room temperature, this lyophilized preparation can be stored in room temperature for 320 days. Our result in a 90 minutes hemorrhagic shock animal model with $2 / 3$ blood volume loss shows that it is superior to whole blood in the following ways: lowering of elevated intracellular $\mathrm{pCO}_{2}$, recovery of ST elevation, protonin levels, lowering of elevated lactate, histology of the heart and intestine. More details in Bian \& Chang JANB 2014 early online full text freely available at http://informahealthcare.com/doi/pdf/10.3109/21691401.2014.964554

International progress up to now shows that it is possible to tailor-make blood substitutes ranging from simple to complex. It is urgent to have these ready without again waiting until it is too late. We need to analyze the specific indications for 1,2 and 3 above. If a condition only needs oxygen then there is no need to use a more complex one. On the other hand, it would be folly not to use a more complex one if indicated. We also need to intensify research on the many important ongoing research around the world (references for these are in the next page). Examples include: develop other novel approaches including novel crosslinkers; new sources of material from porcine, bovine, human cord rbc, recombinant, Arenicola marina; basic research on nitric oxide, oxidative stress, haptoglobin, rate of oxygen supply; safety and efficacy analysis and many other areas. The 2015 XV Int Symposium on Blood Substitute at Lund University (Professor Lief Bulow), Lund, Sweden http://isbs2015.lu.se to be followed by the 2017 XVI at McGill University (Professor TMS Chang), Montreal Canada www.medicine.mcgill.ca/artcell , will be excellent opportunities for international exchanges.

\section{Acknowledgements}

This area of research at the author's laboratory is at present being supported by an operating grant of the Canada Blood Service/Canadian Institutes of Health Research that require the author to state that the opinions in this paper are those of the author and not necessary of the granting agencies or the government of Canada.

The author has no connection to commercial organization.

\section{References}

Bian, Y, Rong, Z and Chang TMS (2011) Artificial Cells, Blood Substitutes \& Biotechnology 39: 127-136

Bian,Y \& Chang TMS (Oct 2014) Artificial Cells, Nanomedicine \& Biotechnology. 43, 1: 1-9

http://informahealthcare.com/doi/pdf/10.3109/21691401.2014.964554

Bucci E (2011). Artificial Cells, Blood Substitutes, and Biotechnology 39:206-213

Buehler PW, Haney CR, Gulati A, Ma L, Hsia CJ.(2004) Free Radical Biology \& Medicine 37 (1), 124-35

Chang, T.M.S. (1957) Hemoglobin corpuscles., Medical Library, McGill University.

Chang, T.M.S. (1964). Science 146:524-525.

Chang, T.M.S., and Poznansky, M.J. (1968). Nature 218:242-245.

Chang, T.M.S. (1971a). Nature 229:117-118. 
Chang, T.M.S. (1971b) Biochem Biophys Res Commun 44:1531-1536.

Chang, TMS (2005).. Nature Review: Drug Discovery 4: 221-235

Chang, TMS (2007) Monograph on "ARTIFICIAL CELLS: World Scientific Publisher/. Free online viewing at www.medicine.mcgill.ca/artcell

Chang,TMS (ed) (2013) Book on Selected Topics in Nanomedicine. World Scientific Publisher. Free Chapter 1 at www.medicine.mcgill.ca/artcell

D’Agnillo, F and Chang, T.M.S. (1998). Nature Biotechnol 16:667-671.

Greenburg AG (2013) in "Selected Topics in Nanomedicine" Editor TMS Chang, World Science

Publisher/Imperial College Press

Gould, SA, Sehgal LR, Sehgal HL, and GS Moss. (1995) Transfu Sci, 16:5-17

Gould SA, EE. Moore, DB. Hoyt, PM. Ness, EJ. Norris, JL. Carson, GA. Hides, IHG Freeman, R DeWoskin and GS. Moss (2002) J. Am. Coll. Surg. 195, 445-452

C. Guo, M.Gynn and TMS Chang (2015). Artificial Cells, Nanomedicine \& Biotechnology 43: (in press)

Hoffman, SJ, DL Looker, JM Roehrich et al.(1990) Proc. Natl. Acad. Sci. U.S.A. 87:8521-8525.

Jia,YP and Alayash Al (2013). in "Selected Topics in Nanomedicine" Editor TMS Chang, World Science

Publisher/Imperial College Press

Jahr JS, Mackenzie C, Pearce LB, Pitman A, Greenburg AG.(2008). J Trauma 64: 1484-97

Kim, HW and AG Greenburg. (2014) Book on HBOC and OxygenTherapeutics. Springer Publisher.

Klein HG The prospects for red-cell substitutes. N Engl J Med. 2000;342(22):1666-68

Kobayashi K, E. Tsuchida, H. Horinouchi [ed] (2005) Artificial Oxygen Carriers, Spring-Verlag Publisher

Liu Q, RJ Xiu (2008) Artificial Cells, Blood Substitutes \& Biotechnology, 36,3:169-293

Lui, FE and R Kluger ChemBiochem (2010) 11 1816-1824.

Ma, L and Hsia CJC (2013) in "Selected Topics in Nanomedicine" TMS Chang (ed), World Science

Publisher/Imperial College Press

Mozzarelli, A \& Bettati,S (eds) (2011) Oxygen Therapeutics Wiley, U.K.

Moore E , Moore FA , Fabian TC, Bernard AC , Fulda GJ , Hoyt DB , et al (2009) J Am Coll Surg. 208: 1-13

Natanson C, Kern SJ, Lurie P, Banks SM, Wolfe SM. (2008). JAMA 299: 2304-12.

Orive G, Hernandez RM, Gascon Arm Calafiorer R Chang TMS (2003) Nature Medicine 9:104-107

Powanda, D., and Chang, T.M.S. (2002) Artificial Cells Blood Substitute Immobil Biotechnol 30:25-42.

Przybelski, R, J Blue, M Nanvaty, C Goldberg, T Estep, and Schmitz T. (1996) Artficial Cells,Blood Substitutes Immb Biotech, 24: 407,

Rousselot M, Delpy E, Drieu La Rochelle C, Lagente V, Pirow R, Rees JF, Hagege A, Le Guen D, Hourdez S, Zal F. (2006). Biotechnol J 1(3): 333-45.

Sakai, H(2013) in "Selected Topics in Nanomedicine" Editor TMS Chang, World Science Publisher/Imperial College Press 
Seetharama A. Acharya, Amy G. Tsai and Marcos Intaglietta (2013) in "Selected Topics in Nanomedicine" Editor TMS Chang, World Science Publisher

Simoni, J, G Simoni, C D.Lox, S D Prien, \& G T Shires.(1997). Artificial cells, Blood Substitutes Immob Biotechnology, 25:193-210, 1997.

Sims C , Seigne P , Menconi M, Monarca J , Barlow C , Pettit J ,Puyana JC . (2001). J Trauma. 51 : 1137 1146 .

Tam ,SC, J Blumenstein, and JT Wong. Dextran Hb. Proc Natl Acad USA, 73:2128, 1976.

Tsuchida E [ed] (1998): Blood Substitutes: Present and Future Perspectives. Amsterdam: Elservier

Wei, G, Bian, YZ, and TMS Chang (2013) J Artificial Cells, Nanomedicine \& Biotechnology 41, 4: 232-239

Weiskopf, RB www.anesthesia-analgesia.org Oct 2014 119:758-760

Winslow RM (ed.). 2006. Blood Substitutes. Amsterdam: Academic Press.

Wong, J.T. (1988) Biomater Artificial Cells Artificial Organs 16:237-245.

Wong, N \& TMS Chang.. Artificial Cells, Blood Substitutes and Biotechnology 2007;35:481-489

Yabuki, A, K. Yamaji, H. Ohki, Y. Iwashita,, Transfusion. 30, 516-20 (1990).

Yang CM, JX Liu, ZG Zheng (2013) XIV Int Sym Blood Substitutes \& Oxygen Therapeutics.

Yu B, M Shahid, EM Egorina, MA Sovershaev, MJ Raher, C Lei, MX Wu, KD Bloch, WM Zapol (2010),

Anesthesiology 112:586 -594

Zapol WM (2011) XIII International Symposium on Blood Substitutes \& Oxygen Therapeutics

Zhu X.L., Chu W, Wang T, Wang F, Fan D, Dan N, Chen C. (2007). Artificial Cells, Blood Substitutes and

Biotechnology 35: 518-532

Zhou W, Zhao L.Wang JF, Li S, Chen G, Liu JX \& Yang CM (2013) J Artificial Cells, Nanomedicine and

Biotechnology, 41:289-292

Zuck, TF (2006) in Winslow (ed) book on Blood Substitutes, Amsterdam: Academic Press 